\title{
Activating the Cognitive Learning Activity through "Dead" Case
}

\section{Andrii O. Vitchenko}

National Defence University of Ukraine named after Ivan Cherniakhovskyi, Kyiv, Ukraine

\section{Anastasiia Yu. Vitchenko}

National Pedagogical Dragomanov University, Kyiv, Ukraine

\section{Iryna V. Izhutova}

National Defence University of Ukraine named after Ivan Cherniakhovskyi, Kyiv, Ukraine

\section{Loryna G. Aleksandrova}

National Pedagogical Dragomanov University, Kyiv, Ukraine

\section{Viktoriia L. Romaniuk}

National Pedagogical Dragomanov University, Kyiv, Ukraine

\begin{abstract}
The authors investigated technologization of educational process in high school and formation of interactive communicative environment for professionally oriented learning. Analysis of the problems of cases use in modern teaching practice was conducted. Methods of questionnaires, empirical data generalization, theoretical analysis of case study, justification of approaches to its technological effectiveness, "dead case", findings generalization, defining prospects of further problem consideration were used. The authors identified the features of case study technological implementation and developed the "dead" case-based study algorithm for development of future lecturers' professional skills. The conditions of the effective use of case technology in high school were defined. The authors proved the integral character of the case technology.
\end{abstract}

Keywords---case technology, educational process, effective scientific, future lecturers, pedagogical work.

Linguistics and Culture Review (c) 2021.

Corresponding author: Vitchenko, A. O; Email: a-vitchenko6069@ust-hk.com.cn

Manuscript submitted: 9 April 202 1, Manuscript revised: 18 June 2021, Accepted for publication: 23 July 2021 


\section{Introduction}

Technologization of educational process in high school and formation of interactive communicative environment for professionally oriented learning contributes to case technology, which is interactive and competence-based, indepth development of self-educated, research, foreign communicative competence, development of group communicative skills, collective discussion of problems and joint solutions, joint success in problem solving, particularly related to mutual understanding and communication. National and foreign researchers prefer to use case technology in a range of academic courses and subjects, including business, economy, management, finances, law, medicine, ecology, and higher professional education (Igbaria et al., 1995; Chien \& Chen, 2008).

Particularly, Rippin et al. (2002), simultaneously consider the case study as leading technology in business education, education method, and effective tool for study and administration of complex and indefinite situations. The approach which developers propose to use cases in online education of modern high school has become innovative. Webb et al. (2005), proved that students KPI raised due to integration of different technologies, extension of case study by interactive discussions. Kelch \& Malupa-Kim (2014), defined teacher's potential due to case study as ability to combine classroom and individual practical tasks, diversify students' foreign language learning activities, "During class time when the case is being discussed, work sheets, jigsaw tasks, mini presentations, and other tasks which are implemented in the case analysis process can be completed for a grade if desired. Participants can be required to complete a comprehension check, write a response paper, or complete another task that is related to content/readings upon which the case is based" (Kelch \& Malupa-Kim, 2014).

Nae (2019), wrote about the use of case study in teaching business English for Master's degree in business students. Having defined the case as learning method, she developed this chain of students education actions based - foreign text reading, listening, learning of additional information, and writing. Nae mentioned, "The writing assignment requires the students to write e-mails or letters reporting on the outcomes of the discussions" (Nae, 2019). Kerr et al., (2020), limited this problem by discussing the use of role game to activate case study in information systems. According to them, "roleplaying allows them to become more involved in the case as well as making the subject easier to understand and more realistic" (Kerr et al., 2003).

The national scientists focus on features of method competence of future lecturers in implementation of intercultural foreign education Maiier (2017), research of process of formation of interactive skills, clarification of interlocutory interaction influence on development of students' language competence Liubashenko \& Kornieva (2019), use of particular case study elements to learn effectiveness of self-assessment and expert assessment of technical university students (Lavrysh, 2016). Sazukina (2016), proposed simplified case study definition as "very effective classroom technique" permitting to develop skills:

- Problem solving.

- Depending on the case analytical tools, quantitative and or qualitative. 
- Decision-making in difficult situations.

- Manage ambiguity.

- Communication with different groups" (Sazukina, 2016). Researchers skipped scientific justification of case study technological effectiveness, algorithmization of approaches to different structure cases, diversification of students' cognitive learning activity with "dead" case (Golitsyna, 2017; Mora et al., 2015).

\section{Material and Method}

Aim is to justify the case study technological effectiveness, consider technological approaches to intensification of future lecturers' cognitive learning activity through "dead" case. To achieve the mentioned aim we have solved the following tasks: analysis problems of cases use in modern teaching practice; features of case study technological implementation; working-out the "dead" case-based study algorithm for development of future lecturers' professional skills; defining conditions of the effective use of case technology in high school. We have used methods of questionnaires, empirical data generalization for defining case use problems in modern high school; theoretical analysis of case study, justification of approaches to its technological effectiveness; "dead case"; findings generalization; defining prospects of further problem consideration (Tudor, 2013; Siegel et al., 2004).

The analysis of modern university practice proved a lot of case study followers among lecturers, Master's degree students, and different leaders. The conducted empirical study (Figure 1) proved that the majority of respondents positively accepted the idea of this technology integration into learning process supporting their choice by authority and high rating of developing university (18\%), necessity to increase own competitiveness by means of educational innovations (24\%), and successful experience of this technology use $(31 \%)$. Meanwhile, only $12 \%$ of respondents were ready to use case study, others doubted because of poor knowledge about technology (43\%), lack of appropriate experience $(21 \%)$, and commitment to traditional learning (16\%) (Grol \& Grimshaw, 2003; Lasauskiene \& Rauduvaite, 2015).

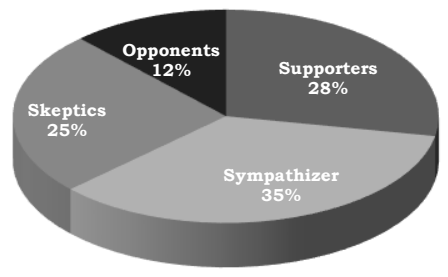

Figure 1. "Case study" questionnaire results in modern high school: pro et contra

Poor theory, simple understanding of case study education potential proved in responses to questions about case, conditions of its use for the highest success in learning. $14 \%$ qualified the case as learning instrument substituting a textbook; 
$18 \%$ qualified it as technology, $33 \%$ considered it as one of the practical learning methods, and one third of respondents $(29 \%)$ could not provide any reasoned definition. Case as "life story" (38\%) is rather demonstrative; it is the basis for interlocution, dialog, collective discussion of some life or professional events (Sahakian \& Seyfang, 2018; Berndtsson et al., 2020). Only $12 \%$ preferred the analysis of problematic situations, elaboration of own solutions for problems, discussion. The analysis of empirical data revealed the reasons of low case study effectiveness in the Ukrainian high school: superficial technology understanding, narrowing goal, lack of algorithm of its implementation, and limitation of types and forms of practical work with cases.

\section{Result and Discussion}

The case study includes the use of different cognitive learning activity of the Master's degree students such as from case reading and additional materials to discussion and creative works (Mozgalova et al., 2021; Biletska et al., 2021). Thus, we consider the case technology as the system method of collective group interactive learning aimed at comprehensive problems learning and solving using the system of methods - reading, analysis, synthesis, generalization, problem method, interlocution, modelling, dramatization, designing, discussion, etc. The case technology consists in consideration of specific ordinary and professional life for in-depth study, group discussion, and joint decision making. The key of this technology is the "case", which consists of specially prepared materials (problem or "case body", situation context, author's comment, questions and tasks, list of recommended sources, and clarity). These elements are necessary to achieve aims such as development students' critical thinking, general and special skills in modelling, design and forecasting; improvement of self-educational, research and communicative skills, creativity development, etc.

The case study effectiveness depends on the case story, its correspondence to future specialists' interests, level of developed certain personal and professional qualities, especially abilities to analyze, conduct a dialog and a discussion. Thus, the learning case writing is in the primary focus. It includes six structural components such as problem situation ("case body"), situation context, author's comment, questions and tasks for individual work, list of recommended sources, and appendixes. The approach to the use of case technology includes problems of learning material, students' readiness to interactive learning, and cases typology. According to the structure, the cases can be "dead" (include all the components or "case body" is partially presented) and "live" (with incomplete structure). We consider "Career and leadership" topic, namely approaches to interactive skills of the future lecturers using the "dead case" within "Margaret Thatcher leadership strategy: listen to everyone or hear everyone".

The Master's degree students receive the case in advance for independent reading, answers preparation and tasks execution. The lecturer uploads materials on online learning platform or internet services for effectiveness and feedback, gives online consultation, and defines time of preliminary control of "case body" learning results, and discussion of problem during practical class. The "case body" text learning is followed by test on "Master test" internet service. Having 
passed the test, the Master's degree students pass to the second phase which covers additional case components:

- Historical context - reconstruction of internal political events in the United Kingdom in the late 60 s and early 70 s, the rise of conservatives power and M. Thatcher's appointment as Education Secretary.

- Author's comment is aimed at evaluation of education policy of conservatives, M. Thatcher's leadership qualities contributing to positive achievements in modernization of the UK school system.

- Questions and tasks system includes in-depth learning of texts, development of practical skills related to authentic English-language texts, citing extracts during staging and dramatization of case events, and participation in problem discussion.

The proposed case included the following system of questions and tasks:

- What is the essence of the problem M. Thatcher faced during the UK school education reform?

- What was the leadership position of the future "Iron Lady" in the implementation of the chosen reform course?

- Do you support M. Thatcher position in the problem? How should we assess the politician actions: she acted as responsible or authoritarian leader? Please, justify your opinion.

- Comment on the M. Thatcher's statement, "It's impossible to understand everyone if we do not hear everyone". What does it mean?

- How would M. Thatcher formulate hew leadership strategy: listen to everyone or hear everyone? Justify your answer?

- Analyze content and style of supporting the reform facts in M. Thatcher's book "The Path to Power", "By 1970 very few children were so deprived that school milk was essential for their nourishment. Tony Barber, who became Chancellor in July 1970, after the death of Iain Macleod, wanted me to abolish free school milk altogether. But I was more cautious, both on political and on welfare grounds. I managed to hold the line at an increased price for school meals and the withdrawal of free milk from primary school children over the age of seven. These modest changes came with safeguards: children in need of milk for medical reasons continued to receive it until they went to secondary school. All in all, I had defended the education budget effectively".

- Are there any alternative approaches to solve the "milk scandal"? If "yes", explain and consult modern politicians on actions in such events.

- Explain terms "leadership", "conservative", "labourite", "education reform", "fiasco", "circular", "discredit", "PR", "political opponent", and "Iron Lady".

- Using the mentioned terms, write the essay "M. Thatcher's leadership strategy: listen attentively, say simply and concisely, convince reasonably".

- Develop a scenario of M. Thatcher's imaginary interview (press conference) concerning "milk scandal". Consider which questions journalists might ask the UK Education Secretary and her answers.

- Stage the written scenario; be ready to ask the best question, best answer, best statement, etc. 
The algorithm of the case use during interactive learning consists of six phases (Figure 2). To gin professional skills the Master's degree students execute different tasks at every: search (reading of sources, content analysis, selection and systematization of new information, note-taking, reconstruction approaches use, and gained knowledge exchange); analytical and synthetic (analysis of problem situation, comparison and critical assessment of facts, fact-finding, drawing conclusions, and substantiation of decisions); prognostic and corrective (forecasting situation development and its related events, explication and correction of own decision considering expected changes); communicative (correct, concise and explicit expression of opinions, reasoned own position and approaches to problem solving, available developed solutions in different styles); creative (generation of new ideas and proposals for problem solving, initiation of original ways and methods for their practical realization, implementation of own views and solutions in different forms); administrative (situation control, proactivity, criticism, attention to alternative opinions and proposals, flexibility and decisiveness, and strong-willed personality).

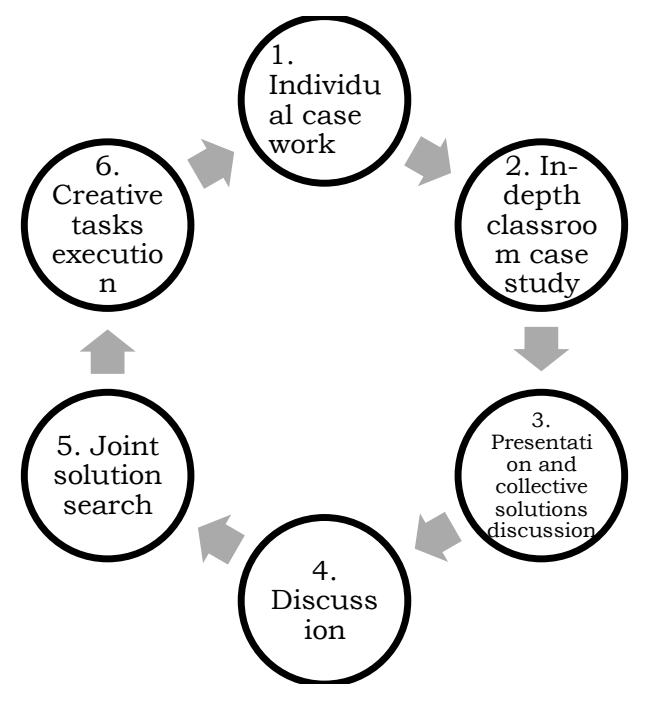

Figure 2. Algorithm of case use in interactive learning

Controversial opinion of some case study researchers concerning technological effectiveness of the studied process as learning method, learning approach, and learning mode. We dispute the conclusion that "case study methodology serves to provide a framework for evaluation and analysis of complex issues" (Healel \& Twycross, 2018). It is worth also considering the opinion that "case study research is defined as a qualitative approach in which the investigator explores a real-life, contemporary bounded system (a case) or multiple bound systems (cases) over time, through detailed, in-depth data collection involving multiple sources of information, and reports a case description and case themes" (Alpi \& Evans, 2019). Firstly, the case technology does not fulfil methodological function as it is based on ideas of interactive, problematic, developing, and competence learning. Secondly, the complex questions analysis and assessment limitation does not allow realizing comprehensively the case study learning potential, 
directing it at development of both key and professional competences of the future specialists with higher education.

D. Zucker demonstrates the controversial position, uses the "case method" and understands it as the situation analysis, stipulating that during case study it necessary to use reading, writing, generalization, comparison, interpretation, etc. in line with analysis. This controversity is visible in the following statement of the American researcher from the University of Massachusetts Amherst, "Case study method is indexed in many introductory research textbooks and is often taught in qualitative research methods courses that discuss a variety of methods. These may include grounded theory, phenomenology, discourse analysis and case study, for example. Reasonable goals for the learner would be to explore and understand the philosophical and aesthetic paradigms that are foundational to qualitative research methods, compare and contrast the distinctions among selected methods, evaluate traditional and emerging qualitative designs within their disciplinary area, and to apply methods and techniques. Using a step-wise approach students will learn how to design studies, generate data, analyze and interpret the data and disseminate findings. The teacher creates a teaching and learning environment to meet those outcomes" (Zucker, 2009). The abovementioned definition of the key term is disputable as it does not correspond to the researched learning innovation and does not consider its structural, procedural, and instrumental features.

\section{Conclusion}

Modern researchers does not pay much attention to problems of formation of favourable learning case study environment, conditions for successful case development (time management; involvement of consultants and experts, events' participants; favourable psychological atmosphere; constructive interpersonal relations; and interactivity of learning communication). They also skip the fact that the case study as interactive technology integrates different learning methods (verbal, visible, practical, game, etc.). it enriches cognitive learning activity, combine self-education and classroom work, learning and research, educational and professional qualities development. Thus, it is necessary to develop algorithmization of case technology-based learning process and implement the outcomes.

Based on the conducted study we have proved the integral character of the case technology which combines basic learning forms and methods, diversifies material learning, ensures the appropriate problematization of content and high level of students' cognitive learning activity. Due to defined advantages the case technology allows intensifying varied interests and motivations of future lecturers, directing formation of readiness to effective scientific and pedagogical work based on professional skills system related to self-education, researches, interactive cooperation and communication. Future research should explore cases typology, development of types and forms of cognitive learning activity through the case study integration and new information technologies. 


\section{References}

Alpi, K. M., \& Evans, J. J. (2019). Distinguishing case study as a research method from case reports as a publication type. Journal of the Medical Library Association: JMLA, 107(1), 1.

Berndtsson, I., Dahlborg, E., \& Pennbrant, S. (2020). Work-integrated learning as a pedagogical tool to integrate theory and practice in nursing education-An integrative literature review. Nurse education in practice, 42, 102685. https://doi.org/10.1016/j.nepr.2019.102685

Biletska, I. O., Paladieva, A. F., Avchinnikova, H. D., \& Kazak, Y. Y. (2021). The use of modern technologies by foreign language teachers: developing digital skills. Linguistics and Culture Review, 5(S2), 16-27.

Chien, C. F., \& Chen, L. F. (2008). Data mining to improve personnel selection and enhance human capital: A case study in high-technology industry. Expert Systems with applications, 34(1), 280-290. https://doi.org/10.1016/j.eswa.2006.09.003

Golitsyna, I. (2017). Educational process in electronic information-educational environment. Procedia-Social and Behavioral Sciences, 237, 939-944. https://doi.org/10.1016/j.sbspro.2017.02.132

Grol, R., \& Grimshaw, J. (2003). From best evidence to best practice: effective implementation of change in patients' care. The lancet, 362(9391), 1225-1230. https://doi.org/10.1016/S0140-6736(03)14546-1

Heale, R., \& Twycross, A. (2018). What is a case study?.

Igbaria, M., Iivari, J., \& Maragahh, H. (1995). Why do individuals use computer technology? A Finnish case study. Information \& management, 29(5), 227-238. https://doi.org/10.1016/0378-7206(95)00031-0

Kelch, K., \& Malupa-Kim, M. (2014). Implementing Case Studies in Language Teacher Education and Professional Development. Ortesol Journal, 31, 10-18.

Kerr, D., Troth, A., \& Pickering, A. (2003). The use of role-playing to help students understand information systems case studies. Journal of Information Systems Education, 14(2), 167-172.

Lasauskiene, J., \& Rauduvaite, A. (2015). Project-based learning at university: Teaching experiences of lecturers. Procedia-Social and Behavioral Sciences, 197, 788-792. https://doi.org/10.1016/j.sbspro.2015.07.182

Lavrysh, Y. (2016). Peer and self-assessment at ESP classes: case study. Advanced education, (6), 60-68.

Liubashenko, O., \& Kornieva, Z. (2019). Dialogic interactive speaking skills assessment in the experiential teaching of technical English to tertiary school students. Advanced Education, 6(13), 18-25.

Maiier, N. (2017). The methodological training of future university teachers to implement intercultural foreign language education: the competency-based approach. Advanced education, 4(8), 4-9.

Mora, H. M., Pont, M. T. S., Casado, G. D. M., \& Iglesias, V. G. (2015). Management of social networks in the educational process. Computers in Human Behavior, 51, 890-895. https://doi.org/10.1016/j.chb.2014.11.010

Mozgalova, N. G., Baranovska, I. G., Hlazunova, I. K., Mikhalishen, A. V., \& Kazmirchuk, N. S. (2021). Methodological foundations of soft skills of musical art teachers in pedagogical institutions of higher education. Linguistics and Culture Review, 5(S2), 317-327. 
Nae, N. (2019). Teaching English With The Case Method-A Tentative Approach. Euromentor Journal-Studies about education, 10(01), 25-38.

Rippin, A., Booth, C., Bowie, S., \& Jordan, J. (2002). A complex case: Using the case study method to explore uncertainty and ambiguity in undergraduate business education. Teaching in Higher Education, 7(4), 429-441.

Sahakian, M., \& Seyfang, G. (2018). A sustainable consumption teaching review: From building competencies to transformative learning. Journal of cleaner production, 198, 231-241. https://doi.org/10.1016/j.jclepro.2018.06.238

Sazukina, T. P. (2016). Case studies method in teaching the professional English language at higher school. Публічне урядування, (1 (2)).

Siegel, D. S., Waldman, D. A., Atwater, L. E., \& Link, A. N. (2004). Toward a model of the effective transfer of scientific knowledge from academicians to practitioners: qualitative evidence from the commercialization of university technologies. Journal of engineering and technology management, 21(1-2), 115142. https://doi.org/10.1016/j.jengtecman.2003.12.006

Tudor, S. L. (2013). The role of multimedia strategies in educational process. Procedia-Social and Behavioral Sciences, 78, 682-686. https://doi.org/10.1016/j.sbspro.2013.04.375

Webb, H. W., Gill, G., \& Poe, G. (2005). Teaching with the case method online: Pure versus hybrid approaches. Decision sciences journal of innovative education, 3(2), 223-250.

Zucker, D. M. (2009). How to do case study research. School of nursing faculty publication series, 2. 